\title{
MANEJO DE COLHEITA E ADUBAÇÃO FOSFATADA NA CULTURA DA ERVA-MATE (Ilex paraguariensis) EM FASE DE PRODUÇÃO
}

\section{HARVEST HANDLING AND PHOSPHATE NUTRITION IN YERBA-MATTE (Ilex paraguariensis) CULTURE DURING PRODUCTION STAGE}

\author{
Delmar Santin ${ }^{1}$ Eliziane Luiza Benedetti ${ }^{2}$ Nairam Félix de Barros ${ }^{3}$ Lucas Leandro Fontes ${ }^{4}$ \\ Igor Carvalho de Almeida ${ }^{5}$ Júlio César Lima Neves ${ }^{6}$ Ivar Wendling ${ }^{7}$
}

\section{RESUMO}

As sucessivas colheitas na base de folhas (FO) e galhos finos (GF), sem a necessária reposição nutricional, têm proporcionado quedas na produtividade brasileira de erva-mate nos últimos 20 anos. Neste sentido, o objetivo do trabalho foi avaliar a influência do intervalo de colheita e da adubação fosfatada na disponibilidade de fósforo $(\mathrm{P})$ no solo, na produtividade e no estado nutricional da erva-mate.O experimento foi conduzido em São Mateus do Sul - PR, em Latossolo Vermelho-Escuro álico, onde se avaliaram doses de 0, 20, 40, 80,160 e $320 \mathrm{~kg} \mathrm{ha}^{-1}$ de $\mathrm{P}_{2} \mathrm{O}_{5}$ para colheitas com intervalos de 12,18 e 24 meses em erval com sete anos. A colheita consistiu na remoção de aproximadamente $95 \%$ da copa formada após a colheita anterior. A massa verde colhida foi determinada individualmente para os componentes FO, GF e galho grosso (GG), sendo FO + GF correspondente à erva-mate comercial (ECOM). Dos componentes da planta, também se avaliou a relação entre massa verde/seca (MV/MS) e teor de P na FO, GF e GG. No momento da colheita coletaram-se amostras de solo nas profundidades de 0-10, 10-20 e 20-40 cm, nas quais se avaliou a disponibilidade de P. A adubação fosfatada elevou a disponibilidade de P no solo nas primeiras camadas e a cultura respondeu positivamente ao nutriente com aumento da produtividade em todos os componentes avaliados. Altas produtividades de ECOM, independentemente do intervalo de colheita, dependem de disponibilidade de $\mathrm{P}$ no solo em nível alto na camada de 0-10 cm. Colheitas com intervalos de tempo maiores resultaram em maiores produtividades de ECOM, mas para maximizar a produtividade, necessita-se de doses mais elevadas de fertilizantes. Intervalos de 12 meses são insuficientes para que a planta se recupere do impacto da colheita, mesmo quando a planta está bem nutrida em fósforo.

Palavras-chave: teor foliar; disponibilidade de fósforo; produtividade; eficiência de utilização do nutriente.

\section{ABSTRACT}

Successive harvesting of leaves (FO) and thin branches (GF), with no nutrient reposition by fertilization,

1 Engenheiro Florestal, PhD., Autônomo, Rua Saulo de Carvalho, 1006, Jardim Esperança, CEP 89460-000, Canoinhas (SC), Brasil. desantinflorestal@yahoo.com.br

2 Engenheira Agrônoma, Dra., Professora do Instituto Federal de Santa Catarina, Av. Expedicionários, 2150, Campo da Água Verde, CEP 89460-000, Canoinhas (SC), Brasil. elibettiagro@yahoo.com.br

3 Engenheiro Florestal, PhD., Professor Titular Aposentado do Departamento de Solos, Universidade Federal de Viçosa, Av. Peter Henry Rolfs, s/n, Campus Universitário, CEP 36570-000, Viçosa (MG), Brasil. nfbarros@ufv.br

4 Graduando em Engenharia Florestal, Centro de Ciências Florestais, Universidade Federal de Viçosa, Av. Peter Henry Rolfs, s/n , Campus Universitário, CEP 36570-000, Viçosa (MG), Brasil. lucas_leandro_fontes@hotmail.com

5 Engenheiro Agrônomo, Autônomo, Rua Prefeito Nascimento Teixeira, 149, Segredo, CEP 36307-404, São João Del Rei (MG), Brasil. igorsolosufv2014@gmail.com

6 Engenheiro Agrônomo, Dr., Professor Associado do Departamento de Solos da Universidade Federal de Viçosa, Av. Peter Henry Rolfs, s/n , Campus Universitário, CEP 36570-000, Viçosa (MG), Brasil. julio_n2003@yahoo. com.br

7 Engenheiro Florestal, Dr., Pesquisador da Embrapa Florestas, Estrada da Ribeira, km 111, s/n, CEP 83411-000, Colombo (PR), Brasil. ivar.wendling@embrapa.br 
have been resulting in continuous decrease in Brazilian productivity of mate in the last 20 years. So, the objective of this work was to evaluate the influence of harvest interval and phosphate nutrition on the availability of phosphorus $(\mathrm{P})$ in the soil, on the productivity, as well as on the nutritional status of mate plants. The experiment was conducted in São Mateus do Sul/PR, in an Oxisol, where doses of 0, 20, 40, 80, 160 and $320 \mathrm{~kg} \mathrm{ha}^{-1}$ of $\mathrm{P}_{2} \mathrm{O}_{5}$ were evaluated for harvest intervals of 12, 18 and 24-months in a seven-yearold mate plantation. Soil P availability, at 0-10, 10-20 and 20-40 cm depth, was assessed. Harvest consisted on removal of approximately $95 \%$ of the tree canopy formed since the previous harvest. Harvested green material was individually determined for FO, GF and thick branches (GG), where FO + GF corresponded to the commercial mate (ECOM). The relationship between green/dry mass (MV/MS) was also evaluated for all plant components, as well as the content of P in FO, GF and GG. Phosphate fertilization increased the availability of $\mathrm{P}$ in the upper soil layer and the plant responded positively to $\mathrm{P}$ application by increasing the dry mass of all the assessed components. Harvests with longer intervals resulted in greater productivity of ECOM, but for maximizing productivity, high doses of fertilizers are needed. Twelve month intervals are insufficient to allow the plant to recover from the harvest impact, even if well-nourished in phosphorus. Keywords: foliar content; phosphorus availability; productivity; nutrient use efficiency.

\section{INTRODUÇÃO}

A exploração da erva-mate (Ilex paraguariensis), espécie que ocorre predominantemente na Região Sul do Brasil (CARVALHO, 2003), teve início antes do ano de 1800 e, em 1902 representava 98\% da produção de riqueza no estado do Paraná (DEITOS, 2007). Fonte de renda para centenas de milhares de trabalhadores sulinos (GAZETA GRUPO DE COMUNICAÇÕES, 1999), esta cultura encontra-se em pleno declínio produtivo nessa região.

O fato de a erva-mate ocorrer naturalmente em ambiente de mata (CARVALHO, 2003), fez do extrativismo o principal modelo de exploração da cultura. Nesse modelo, a ciclagem de nutrientes do ambiente nativo era suficiente para manter produtivo os esparsos indivíduos de erva-mate colhidos a cada 3 a 4 anos. Esse manejo foi mantido até o final da década de 80, pois o avanço da fronteira agrícola incentivou a drástica redução das áreas de ervais nativos. No intuito de atender à demanda por matéria-prima, parte dos ervais nativos foi manejada, retirando-se outras espécies presentes e introduzindo novas plantas de erva-mate, originando cultivos mais adensados (DA CROCE; FLOSS, 1999). Dos anos 90 em diante surgiram cultivos a pleno sol com alta densidade de plantas (ANDRADE, 1999). À medida que se aumentou a densidade de plantas por área, reduziu-se o intervalo entre colheitas, sendo o de 12 e 18 meses os mais praticados (DA CROCE; FLOSS, 1999; CARVALHO, 2003). Essas mudanças na estrutura de condução e manejo de cultivos intensificaram a exportação de nutrientes da área, sem que houvesse preocupação em repô-los. O fator nutricional, talvez seja o que mais tenha contribuído na redução de mais de $60 \%$ da produtividade brasileira nos últimos 22 anos (IBGE, 2015).

Os relatos de que a erva-mate ocorre naturalmente em solos de baixa fertilidade (CARVALHO, 2003) justificavam a possível ausência de resposta da erva-mate à adubação fosfatada. Na década de 80 do século passado, Reissmann et al. (1983) ao caracterizarem nutricionalmente ervais nativos adultos, com intervalo de colheita de 24 meses sem tratos silviculturais, verificaram que as plantas com teor foliar médio de $1,1 \mathrm{~g} \mathrm{~kg}^{-1}$ de $\mathrm{P}$ e disponibilidade no solo de $1,5 \mathrm{mg} \mathrm{dm}^{-3}$ não apresentavam sintomas de deficiência em P. Nesta condição, os autores sugeriram que a erva-mate poderia estar com deficiência oculta em $\mathrm{P}$ ou que essa baixa exigência seria característica da própria espécie. Radomski et al. (1992), ao avaliarem o teor foliar de nutrientes em plantas jovens de erva-mate em condição natural com disponibilidade de P no solo de $0,2 \mathrm{mg}$ $\mathrm{dm}^{-3}$, também sugeriram que esta espécie poderia ser pouco exigente em P. No entanto, resposta positiva de mudas a altas doses de P (SANTIN et al., 2008) e com crescimento máximo quando o teor de P no solo se situava em nível muito alto (SANTIN et al., 2013), sinaliza que cultivos em fase de produção poderiam também responder à adubação fosfatada. Contudo, em solo com disponibilidade de $4,2 \mathrm{mg} \mathrm{dm}^{-3} \mathrm{de}^{\mathrm{P}}$, Pandolfo et al. (2003) não obtiveram resposta da erva-mate ao nutriente. Em levantamento de produtividade de erva-mate em 20 municípios nos três estados do Sul do Brasil, a máxima produtividade de 35,7 e $32,7 \mathrm{t} \mathrm{ha}^{-1}$ ano $^{-1}$ foi obtida em solos com teor de P, respectivamente de 30,0 e 7,0 mg dm${ }^{-3}$ (LOURENÇO, 1997). De certa forma, as escassas informações sobre a demanda por $P$ pela cultura em condições de campo 
são contraditórias.

Apesar de a erva-mate apresentar baixo teor foliar de P, na década de 80, Reissmann et al. (1985) já alertavam que a exportação de nutrientes da área é expressiva, devido ao produto da colheita ser constituído principalmente por folhas e galhos finos, nos quais estão os maiores teores de nutrientes. Daquela época até hoje, raros foram os experimentos a campo com adubação dessa cultura. Apesar disso, em 2004 foi lançada a recomendação de adubação para a cultura da erva-mate para os estados do Rio Grande do Sul e Santa Catarina, em que a dose máxima é de $20 \mathrm{~kg} \mathrm{ha}^{-1} \mathrm{de}_{2} \mathrm{O}_{5}$ (CQFS-RS/SC, 2004). Esta dose parece baixa, tendo em vista a alta afinidade do $\mathrm{P}$ com as argilas, principalmente nos solos mais intemperizados (SANTOS et al., 2008), nos quais grande parte do P aplicado pode ser adsorvida pelas argilas do solo, permanecendo pequenas proporções disponíveis à planta (GONÇALVES et al., 1985). Nessas condições, a dose de $20 \mathrm{~kg} \mathrm{ha}^{-1}$ de $\mathrm{P}_{2} \mathrm{O}_{5}$, aplicada a cada intervalo de colheita, em solos com nível de $\mathrm{P}$ muito baixo, não aumentaria de modo significativo a disponibilidade do nutriente.

Este trabalho teve por objetivo avaliar a resposta da erva-mate em ervais manejados com diferentes intervalos de colheita e submetidos à adubação fosfatada.

\section{MATERIAL E MÉTODOS}

O experimento foi conduzido no município de São Mateus do Sul - PR, localizado no segundo Planalto Paranaense (longitude 50 $32^{\prime} 15^{\prime \prime} \mathrm{O}$ e latitude de $25^{\circ} 54^{\prime} 15^{\prime \prime} \mathrm{S}$, a $800 \mathrm{~m}$ de altitude), sob clima temperado $(\mathrm{Cfb})$, com precipitação pluvial média anual entre 1600 a $1800 \mathrm{~mm}$ (INSTITUTO AGRONÔMICO DO PARANÁ, 1994). O solo do local era um Latossolo Vermelho-Escuro álico, que apresentava disponibilidade de $\mathrm{K}, \mathrm{Ca}$ e $\mathrm{Mg}$ em nível baixo; $\mathrm{P}$ em nível muito baixo (COMISSÃO DE QUÍMICA E FERTILIDADE DO SOLO, 2004) e com alta disponibilidade de Al, características de solo de baixa fertilidade (Tabela 1).

TABELA 1: Teor de argila e propriedades químicas do solo de 0 a $20 \mathrm{~cm}$ de profundidade no local do experimento.

TABLE 1: Clay content and soil properties from 0-20 $\mathrm{cm}$ depth at the experimental site.

\begin{tabular}{|c|c|c|c|c|c|c|c|c|}
\hline $\mathrm{CO}$ & $\mathrm{pH}$ & $\mathrm{Al}^{3+}$ & $\mathrm{H}+\mathrm{Al}$ & $\mathrm{CTC}_{\mathrm{pH} 7,0}$ & $\mathrm{~V}$ & $\mathrm{~m}$ & Argila & $\mathrm{K}$ \\
\hline $\mathrm{g} \mathrm{kg}^{-1}$ & $\mathrm{H}_{2} \mathrm{O}$ & \multicolumn{3}{|c|}{ - - - - - - cmol $\mathrm{dm}^{-3}$ - - . - - - } & \multicolumn{3}{|c|}{ - - - - - - - - - - - - - } & $\mathrm{mg} \mathrm{dm} \mathrm{d}^{-3}$ \\
\hline 31,22 & 3,92 & 4,47 & 15,78 & 17,28 & 8,6 & 71,2 & 77,0 & 56,8 \\
\hline $\mathrm{Ca}^{2+}$ & $\mathrm{Mg}^{2+}$ & $\mathrm{P}$ & ${\mathrm{S}-\mathrm{SO}^{2-}}_{4}$ & $\mathrm{Cu}$ & $\mathrm{Zn}$ & $\mathrm{Fe}$ & $\mathrm{Mn}$ & B \\
\hline \multicolumn{2}{|c|}{$---\mathrm{cmol}_{\mathrm{c}} \mathrm{dm}^{-3}-\ldots$} & \multicolumn{7}{|c|}{ 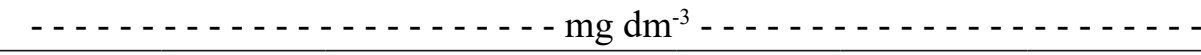 } \\
\hline 0,95 & 0,39 & 1,31 & 7,78 & 14,42 & 2,61 & 74,23 & 26,32 & 0,64 \\
\hline
\end{tabular}

Em que: Extratores: Mehlich-1 (P, K, Fe, Mn, Cu e Zn); KCl (Ca, Mg e Al); Calcinação e solução de $\mathrm{HCl}$ (B) e Fosfato de cálcio (S).

O erval foi estabelecido no ano de 2001, em espaçamento de 2 × 2 m entre plantas e linhas. Na área se encontravam além da erva-mate plantada, esparsos indivíduos de erva-mate nativa e de araucária. A primeira colheita de erva-mate (poda de formação) foi efetuada 24 meses após o plantio a, aproximadamente, $1 \mathrm{~m}$ de altura do solo, e as demais colheitas efetuadas a cada 18 meses até o momento da instalação do experimento. $\mathrm{Na}$ área nunca foi realizada calagem e adubações. A limpeza do erval foi realizada com roçadas mecânicas nos meses de setembro, janeiro e abril de cada ano.

Logo após a colheita, em janeiro de 2009, o experimento foi instalado e avaliaram-se colheitas com intervalos de 12, 18 e 24 meses e seis doses de fósforo, da fonte superfosfato triplo $\left(42 \%\right.$ de $\mathrm{P}_{2} \mathrm{O}_{5}$ e $9 \%$ de Ca). As doses consistiram em 0, 20, 40, 80, 160 e $320 \mathrm{~kg} \mathrm{ha}^{-1}$ de $\mathrm{P}_{2} \mathrm{O}_{5}$. No momento da instalação do experimento, aplicou-se, superficialmente em área total, $1 \mathrm{t} \mathrm{ha}^{-1}$ de calcário dolomítico $(32,5 \% \mathrm{de} \mathrm{CaO}$ e 21,4 \% de MgO), conforme CQFS-RS/SC (2004). Como adubação de base de N e K aplicaram-se 80 kg 
$\mathrm{ha}^{-1}$ de $\mathrm{N}$ e de $\mathrm{K}_{2} \mathrm{O}$, respectivamente, na forma de ureia $(45 \%$ de $\mathrm{N})$ e cloreto de potássio $\left(60 \%\right.$ de $\left.\mathrm{K}_{2} \mathrm{O}\right)$.

Os tratamentos foram arranjados no fatorial $3 \times 6 \mathrm{em}$ esquema de parcela subdividida, com três intervalos de colheita e seis doses de $\mathrm{P}_{2} \mathrm{O}_{5}$, sendo a parcela constituída pelos intervalos de colheita e a subparcela pelas doses. Cada unidade experimental foi composta por 10 plantas úteis, com duas linhas de bordadura. Os tratamentos foram dispostos no delineamento blocos casualizados, com cinco repetições.

A adubação complementar e as doses de $\mathrm{P}_{2} \mathrm{O}_{5}$ foram parceladas, sendo aplicadas superficialmente na área da projeção da copa sem incorporação, sempre no início dos meses de janeiro e setembro. Na colheita com intervalo de 12 meses, as doses de $\mathrm{P}_{2} \mathrm{O}_{5}$ e a adubação complementar foram parceladas em duas vezes. Para as colheitas com intervalo de 18 e 24 meses, as doses de $\mathrm{P}_{2} \mathrm{O}_{5}$ foram parceladas em três vezes e a adubação complementar em duas vezes (duas primeiras aplicações). Na colheita com intervalo de 24 meses, a última parcela da dose foi aplicada quatro meses antes da colheita.

Uma amostra de solo em cada parcela, composta por 15 amostras simples coletadas em três pontos na área da projeção da copa de cinco plantas, foi obtida no momento da colheita (camadas de 0-10, 10-20 e 20-40 cm). O solo da camada de 0-10 cm foi coletado com pá de corte, em uma faixa de $20 \mathrm{~cm}$ de largura por $3 \mathrm{~cm}$ de espessura. Em seguida, nos mesmos pontos foi coletado solo com trado holandês nas demais camadas. O solo foi seco ao ar, passado em peneira com malha de $2 \mathrm{~mm}$ e analisado para determinar o $\mathrm{P}$ disponível utilizando-se extrator Mehlich-1 e quantificado por colorimetria pela redução do fosfomolibdato pela vitamina C (BRAGA; DE FILIPPO, 1974).

Antes da colheita, coletaram-se amostras de folhas (FO) e galhos finos (GF) na metade da altura da copa para determinação da relação entre massa verde e seca e do teor de P. No momento da colheita, em cada parcela retirou-se uma amostra representativa de galhos grossos (GG), para essas mesmas determinações. A FO foi separada do GF e após quantificar a massa verde o material foi lavado, seco a $65^{\circ} \mathrm{C}$ até peso constante, pesada a massa seca e passado em moinho tipo Wiley com peneira de $0,5 \mathrm{~mm}$ de abertura. $\mathrm{O}$ $\mathrm{P}$ total no tecido vegetal foi obtido mediante digestão nitroperclórica e determinado por colorimetria pela redução do fosfomolibdato pela vitamina C (BRAGA; DE FILIPPO, 1974).

Foi efetuada uma colheita para cada intervalo de 12, 18 e 24 meses, respectivamente, em jan/2010, ago/2010 e jan/2011. A colheita foi realizada retirando-se aproximadamente $95 \%$ da massa verde, da qual foi separada a erva-mate comercial $(\mathrm{ECOM}=\mathrm{FO}+\mathrm{GF})$ do $\mathrm{GG}$ e determinada a quantidade de massa verde de ambos. O corte para a colheita foi efetuado entre 10 a $15 \mathrm{~cm}$ acima da posição da última poda. Considerouse como GF, os galhos com diâmetro menor de $7 \mathrm{~mm}$, aproximadamente, e acima deste diâmetro como GG.

Quantificou-se a produtividade de massa verde dos componentes, FO, GF, GG e ECOM. Para a ECOM foi também calculada a produtividade: 1) influenciada pelos intervalos de colheita (ECOM.PIC = produtividade na dose zero em cada intervalo de colheita); e 2) influenciada pela dose (ECOM.PID = produtividade incrementada pela adubação (ECOM.PID = ECOM - ECOM.PIC)). A relação entre peso de massa verde e seca (MV/MS) foi calculada para FO (FO.MV/MS) e ECOM (ECOM.MV/MS).

A eficiência de utilização de P (EUP) foi calculada pela razão entre massa seca dos componentes colhidos da planta (ECOM+GG) e o conteúdo do nutriente acumulado $\left(\mathrm{kg} \mathrm{kg}^{-1}\right.$ de P) (BARROS et al., 1986). A Taxa de recuperação de $P$ do fertilizante pela planta (TR.pl) foi calculada pela fórmula:

$$
T R \cdot p l=\left(\frac{\text { Cont.Ppl.A-Cont.Ppl.NA }}{D \cdot P}\right) \times 100
$$

Em que: TR.pl = taxa de recuperação de $\mathrm{P}$ do fertilizante pelas plantas; Cont.Ppl.A = conteúdo de $\mathrm{P}$ nas plantas adubadas; Cont.Ppl.NA = conteúdo de P nas plantas não adubadas; e D.P = dose de P aplicada.

$\mathrm{Na}$ análise estatística de características do solo, os fatores - intervalo de colheita, dose e camada, compuseram, respectivamente, parcela, subparcela e subsubparcela. Para as características da planta, os fatores - intervalo de colheita e dose, compuseram, respectivamente, parcela e subparcela. Os dados foram submetidos à Anova. As médias referentes ao efeito do intervalo de colheitas foram comparadas pelo teste de Tukey $(\mathrm{p}<0,05)$ e o efeito da dose de $\mathrm{P}$ avaliado por análise de regressão. Para o $\mathrm{P}$ do solo, no desdobramento das interações entre o fator da parcela e subparcela e ou subsubparcela (camada), no sentido de avaliar o efeito da subparcela dento da parcela e/ou subsubparcela, adotou-se como erro o quadrado médio do resíduo combinado e o respectivo número de graus de liberdade, conforme Satterthwaite (1946). 


\section{RESULTADO E DISCUSSÃO}

\section{Fósforo disponível no solo}

A disponibilidade de $\mathrm{P}$ no solo aumentou nas camadas mais superficiais com a aplicação do fertilizante (Figura 1). Na profundidade de $0-10 \mathrm{~cm}$, cujo aumento foi mais expressivo, atingiu os teores de $12,6,11,1 \mathrm{e} 10,1 \mathrm{mg} \mathrm{dm}^{-3}$, respectivamente, nos intervalos entre colheitas de 18,12 e 24 meses na maior dose testada (Figura 1a).

O pequeno aumento da disponibilidade de $\mathrm{P}$ na camada de 10-20 $\mathrm{cm}$ (Figura 1b), sem alterações na camada mais profunda (Figura 1c), reflete a alta afinidade de ligação do elemento com a argila do solo. Em solos altamente intemperizados, predominam as formas inorgânicas de $\mathrm{P}$ ligadas à fração mineral com alta energia e as formas orgânicas estabilizadas física e quimicamente (NOVAIS; SMYTH, 1999; NOVAIS; MELLO, 2007; RHEINHEIMER et al., 2008). Essas propriedades dificultam a mobilidade de P do solo aplicado via fertilizantes, favorecendo a formação de um gradiente com maior concentração do nutriente na camada superficial (RHEINHEIMER; ANGHINONI, 2003; TIECHER et al., 2012). A alta acidez (SOUZA et al., 2006) e disponibilidade de $\mathrm{Al}$ e $\mathrm{Fe}$ também favorecem a precipitação de $\mathrm{P}$ em formas não disponíveis para as plantas (VILAR et al., 2010), características que podem ter contribuído na adsorção de P e limitado
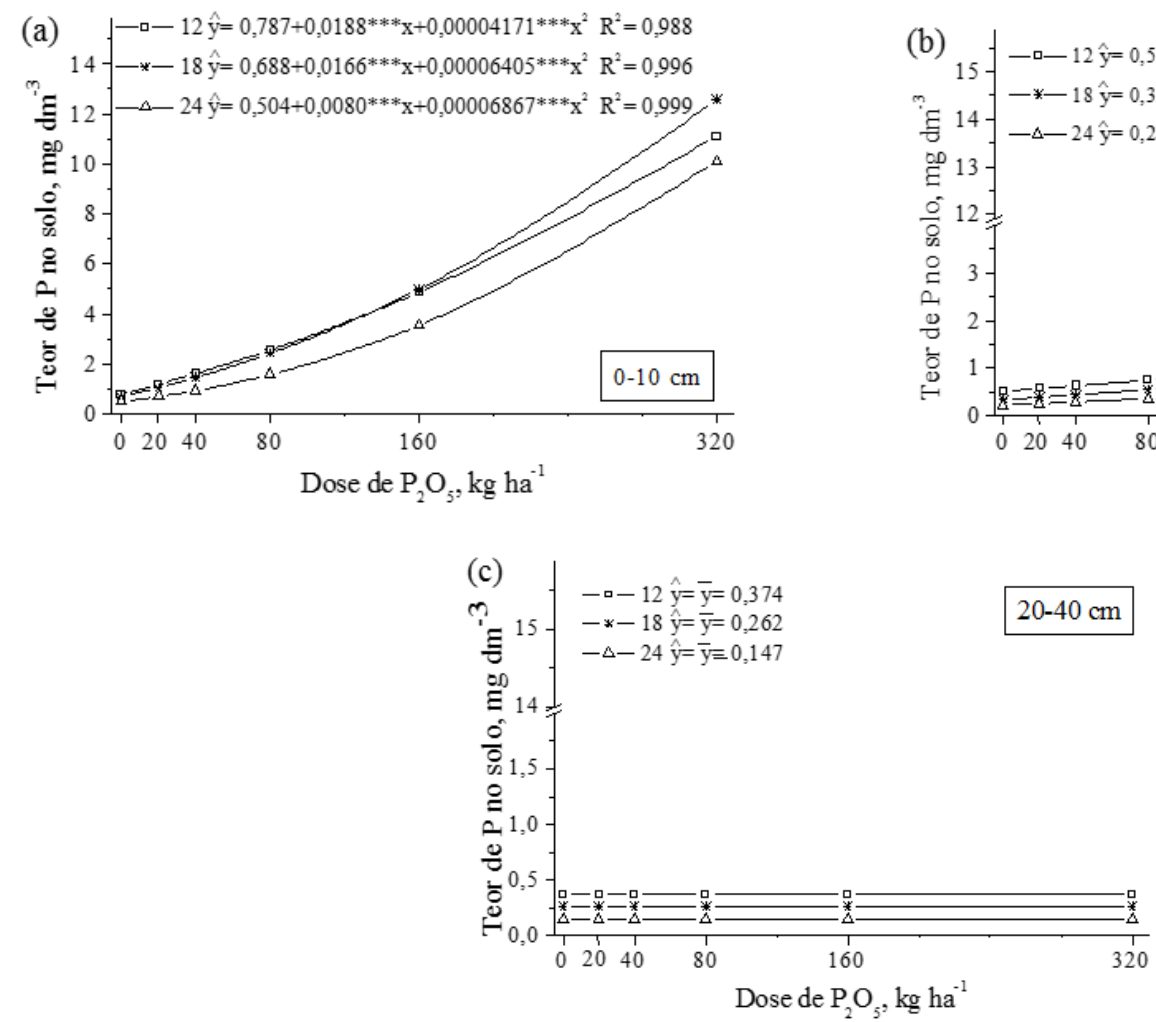

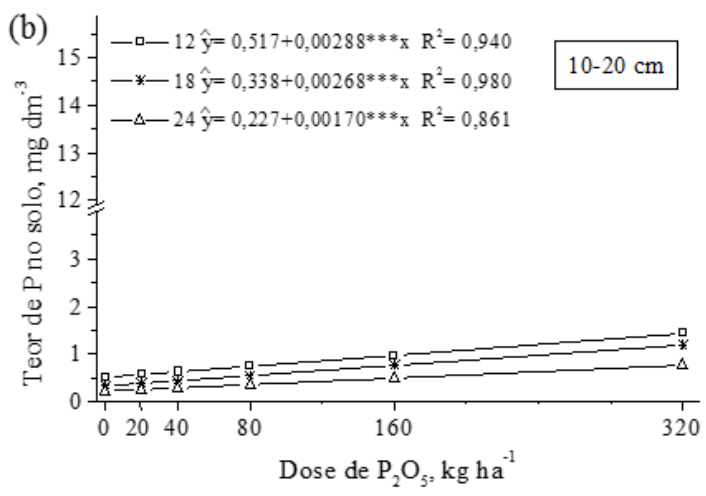

$-40 \mathrm{~cm}$

FIGURA 1: Teor de P no solo extraído por Mehlich-1 nas camadas de 0-10 cm (a), 10-20 cm (b) e 20-40 $\mathrm{cm}$ (c) para colheitas com intervalos de 12,18 e 24 meses em plantio de erva-mate submetido à adubação fosfatada. $* * *$, significativo a $0,1 \%$ de probabilidade.

FIGURE 1: P content in soil extracted by Mehlich-1 at 0-10 cm (a), 10-20 cm (b) and 20-40 cm (c) for harvests at 12,18 and 24 months intervals in mate plantation under fertilization. ***, significant at $0.1 \%$ of probability. 
sua mobilidade no solo neste trabalho.

Normalmente, solos com baixa disponibilidade de $\mathrm{P}$ e com propriedades favoráveis a sua adsorção, a maior parte do P aplicado é imobilizada pelo solo. No entanto, adubações fosfatadas sucessivas ou em altas doses, tendem a saturar os sítios adsortivos de maior energia, permitindo que parte do $\mathrm{P}$ permaneça ligada com menor energia à fase sólida, proporcionando maior aumento na disponibilidade de $\mathrm{P}$ (RHEINHEIMER et al., 2000). Isso explica os aumentos mais expressivos de $\mathrm{P}$ na maior dose na camada superficial (Figura 1a).

A adsorção específica entre o $\mathrm{P}$ e óxidos contribui para sua baixa mobilidade no solo (SCWERTMANN; TAYLOR, 1989; NOVAIS; SMYTH, 1999; NOVAIS et al., 2007; RHEINHEIMER et al., 2008). Com essas características não se esperaria que a adubação fosfatada aplicada superficialmente alterasse a disponibilidade de $\mathrm{P}$ abaixo da camada de $0-10 \mathrm{~cm}$ de solo. A condução da erva-mate com tratos silviculturais e colheitas sem ações mecânicas na área, favorece a boa estruturação do solo, que somada à camada de serapilheira formada por plantas espontâneas e por resíduos de colheitas anteriores, estimula a atividade biológica. Em sistemas que preservam as estruturas do solo é possível a movimentações de $\mathrm{P}$ em profundidade via canais formados pela ação da fauna do solo e pela morte de raízes de plantas (CHEPKWONY et al., 2001). Nessa condição, a movimentação de P para a camada de 10-20 cm ocorreu, possivelmente, através de pequenos canais formados pela macrofauna e ou morte e decomposição de raízes na renovação radicular da própria erva-mate.

\section{Produtividade e status nutricional de fósforo da erva-mate}

A erva-mate respondeu positivamente às doses do fertilizante fosfatado, com aumento da produtividade de FO, GF, GG e ECOM, nos três intervalos de colheita (Figuras 2a, b, c, d). Em todos os componentes, no intervalo de colheita de 24 meses ocorreu a maior produtividade e no de 12 meses a menor.

As doses do fertilizante para maximizar a produtividade dos componentes variaram com o intervalo de colheita. No intervalo de 24 meses, somente a produtividade de GF foi maximizada em doses menores de $320 \mathrm{~kg} \mathrm{ha}^{-1}$ de $\mathrm{P}_{2} \mathrm{O}_{5}$. Nos intervalos de 18 e 12 meses, a máxima produtividade dos componentes ocorreu entre doses, respectivamente, de 278-300 e 211-222 kg ha-1 de $\mathrm{P}_{2} \mathrm{O}_{5}$.

A ordem crescente de máxima produtividade obtida de cada componente, respectivamente para os intervalos de 12, 18 e 24 meses, foi GF com 2,7, 3,0 e 4,3 t ha-1 (Figura 2b); GG com 1,9, 4,2 e 10,2 t ha-1 (Figura 2c); FO com 7,7, 10,4 e 19,3 $\mathrm{t} \mathrm{ha}^{-1}$ (Figura 2a) e ECOM de 10,4, 13,4 e 23,6 t ha-1 (Figura 2d). A superioridade da produtividade de todos os componentes para o intervalo de 24 meses é dependente também de doses mais elevadas de fertilizante fosfatado, quando comparado aos demais intervalos de colheita. A maximização da produtividade de ECOM e GG para colheita com intervalo de 24 meses, ocorreu além do espaço experimental. Desta forma, não permite inferir com segurança qual o potencial produtivo do cultivo nesse intervalo de colheita, sendo necessárias doses mais elevadas para maximizar a produtividade desses componentes.

No desmembramento da produtividade ECOM, analisando isoladamente o efeito do intervalo de colheita (ECOM.PIC) (Figura 2e) e da dose (ECOM.PID) (Figura 2f), é evidente a participação de cada fator na produtividade da planta. A ECOM.PIC, sem diferença estatística e inferior para intervalo de 12 e 18 meses, quando comparada à de 24 meses, indica que, quando a erva-mate não é adubada, a planta só consegue se recuperar do impacto da colheita anterior quando o tempo entre colheitas é mais longo (Figura 2e). Contudo, a máxima ECOM.PID de 4,1 e 6,3 t ha- ${ }^{-1}$, respectivamente, no intervalo de 12 e 18 meses entre colheitas, mostra a importância da adubação fosfatada na recuperação da planta, principalmente para o intervalo de 18 meses (Figura 2f). Mas com ECOM.PID máxima de 11,2 t ha ${ }^{-1}$, o intervalo de 24 meses ainda foi o que proporcionou maior produção pelo efeito dose.

A eficiência de utilização do $\mathrm{P}$ (EUP) diminuiu à medida que se aumentaram as doses do fertilizante. No intervalo de colheita de 12 meses, a EUP mínima ( $737 \mathrm{~kg} \mathrm{~kg}^{-1}$ de P) ocorreu na maior dose testada. Já nos intervalos de colheitas de 18 e 24 meses, a EUP mínima, respectivamente, de 921 e $861 \mathrm{~kg} \mathrm{~kg}^{-1} \mathrm{de} \mathrm{P}$

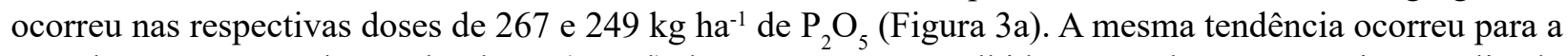
taxa de recuperação do P pela planta (TR.pl) dos componentes colhidos, em relação ao nutriente aplicado pela adubação. Ou seja, a TR.pl reduziu com aumento das doses, entretanto, aumentou com o aumento do 

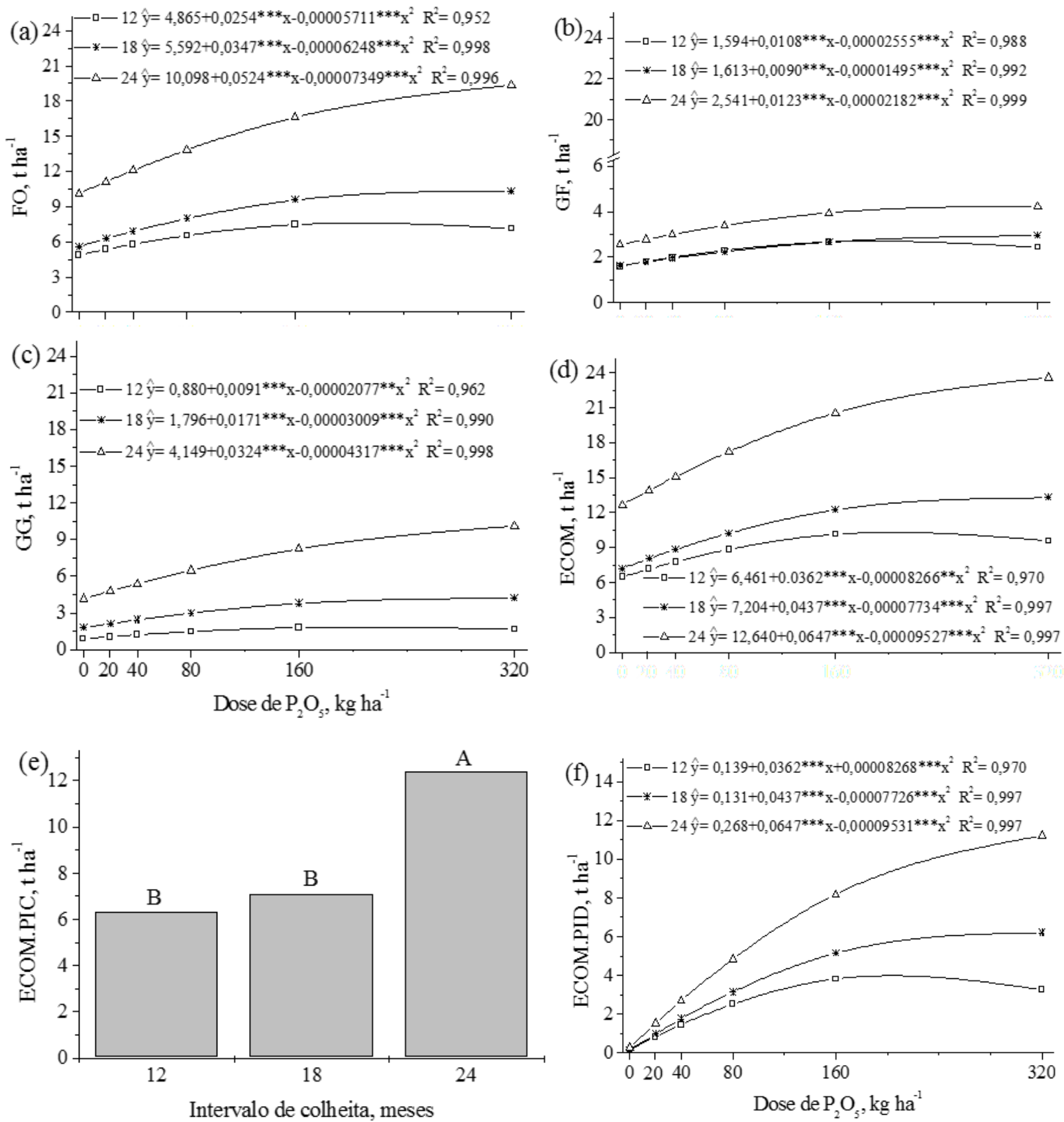

FIGURA 2: Produtividade de massa verde de folhas (FO) (a), galhos finos (GF) (b), galhos grossos (GG) (c) e erva-mate comercial (ECOM) (d); produtividade de ECOM pelo efeito do intervalo de colheita (ECOM.PIC) (e) e pelo efeito da dose (ECOM.PID) (f) para colheitas com intervalos de 12,18 e 24 meses em plantio de erva-mate submetido à adubação fosfatada. ** e ***, respectivamente, significativo a 1 e $0,1 \%$ de probabilidade. Médias seguidas por uma mesma letra na coluna não diferem estatisticamente $(\mathrm{p}<0,05)$ pelo teste de Tukey.

FIGURE 2: Productivity of green leaves (FO) (a), thin branches (GF) (b), thick branches (GG) (c) and commercial mate (ECOM) (d); ECOM productivity affected by harvest interval (ECOM.PIC) (e) and dose effect (ECOM.PID) (f) in mate plantation with 12, 18 and 24 months intervals between harvests under fertilization. $* *$ and $* * *$ respectively, significant at 1 and $0.1 \%$ of probability. Means followed by the same letter in the column do not differ statistically ( $p$ $<0.05$ ) by Tukey test. 
intervalo de tempo entre colheitas (Figura 3f). A TR.pl mínima de 1,5, 3,2 e 5,6 \%, respectivamente, nos intervalos de colheita de 12, 18 e 24 meses ocorreu na maior dose de adubação.

$\mathrm{Na}$ relação entre massas, verde e seca (MV/MS), os componentes FO (Figura 3b) e ECOM (Figura 3c) foram afetados pelo intervalo de colheita e dose. Porém, a MV/MS da FO e da ECOM só foi influenciada pela adubação no intervalo de 18 meses, apresentando relação mínima de 3,1, respectivamente na dose de 268 e $265 \mathrm{~kg} \mathrm{ha}^{-1}$ de $\mathrm{P}_{2} \mathrm{O}_{5}$. A relação entre os componentes FO/GF, os quais formam a ECOM, somente
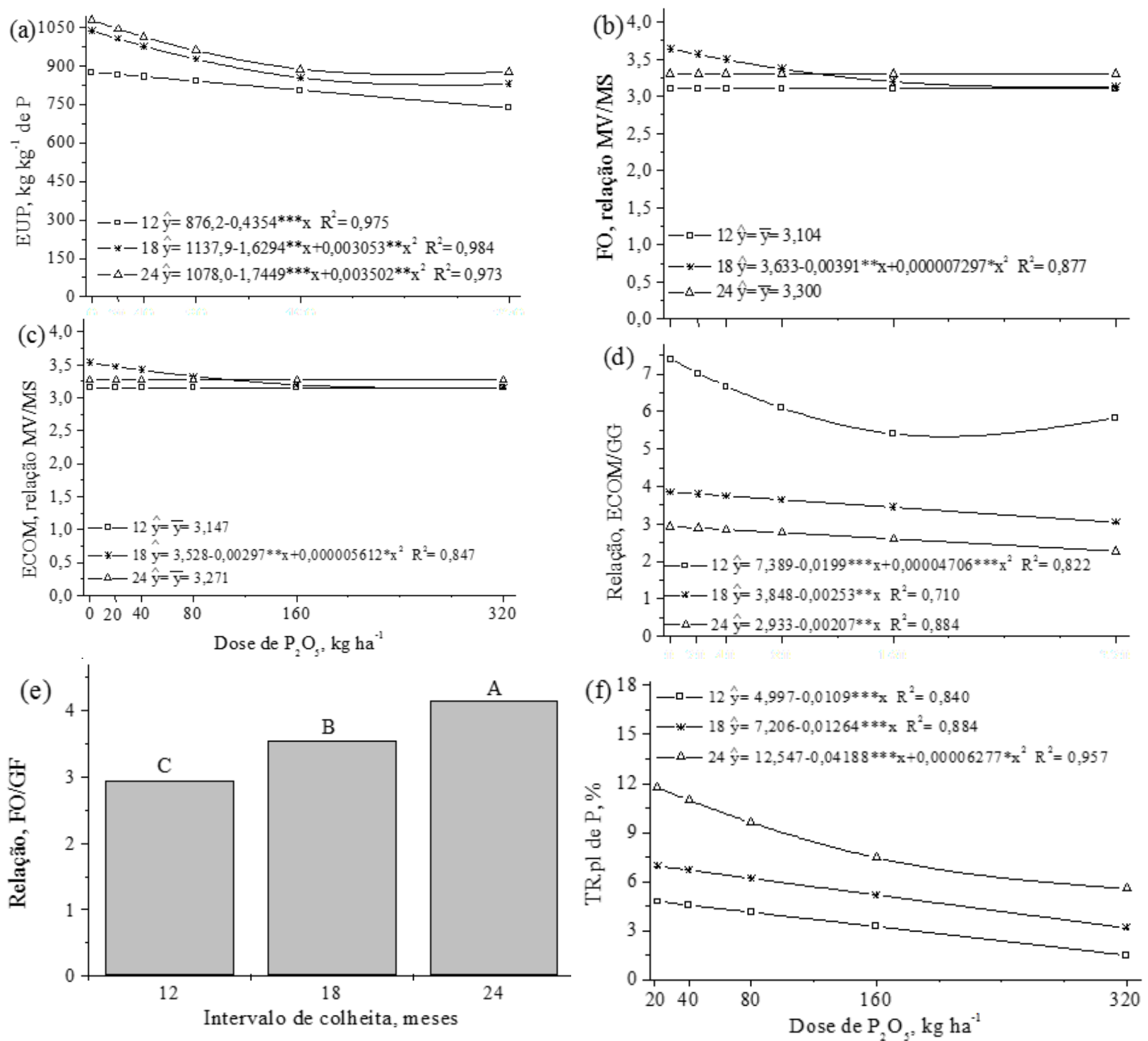

FIGURA 3: Eficiência da utilização de P (EUP) (a); relação entre massa verde e seca (MV/MS) de folha (FO) (b) e de ECOM (c); relação entre componentes, ECOM/GG (d) e FO/GF (e); e taxa de recuperação de P pela planta (TR.pl) (f) para colheitas com intervalos de 12, 18 e 24 meses em plantio de erva-mate submetido à adubação fosfatada. *, ** $\mathrm{e}^{* * *}$, respectivamente, significativo a 5, 1, 0,1 \% de probabilidade. Médias seguidas por uma mesma letra não diferem estatisticamente $(\mathrm{p}<0,05)$ pelo teste de Tukey.

FIGURE 3: P use efficiency (EUP) (a); relationship between green and dry mass (MV/MS) of leaves (FO) (b) and ECOM (c); relationship between components, ECOM/GG (d) and FO/GG (e); and plant $\mathrm{P}$ recovery rate (TR.pl) (f) in mate plantation with 12, 18 and 24 months intervals between harvests under fertilization. $* * *$ and $* * *$ respectively, significant at $5,1,0.1 \%$ probability. Means followed by the same letter do not differ statistically $(\mathrm{p}<0.05)$ by Tukey test. 
foi afetada pelo intervalo de colheita (Figura 3e), tendo o intervalo de 12 meses relação inferior $(2,9)$ e o intervalo de 24 meses superior aos demais com 4,2. Já na ECOM/GG, além do intervalo de colheita, as doses também afetaram a relação, reduzindo os valores com as doses (Figura 3d). Nos intervalos de 18 e 24 meses, respectivamente, com ECOM/GG mínima de 3,1 e 2,3 ocorridas na dose máxima e no intervalo de 12 meses, o mínimo de 5,3 ocorreu na dose de $212 \mathrm{~kg} \mathrm{ha}^{-1}$ de $_{2} \mathrm{O}_{5}$. A que tudo indica, tanto a adubação quanto o intervalo de colheita são fatores que estimulam um maior aumento de produtividade de GG em
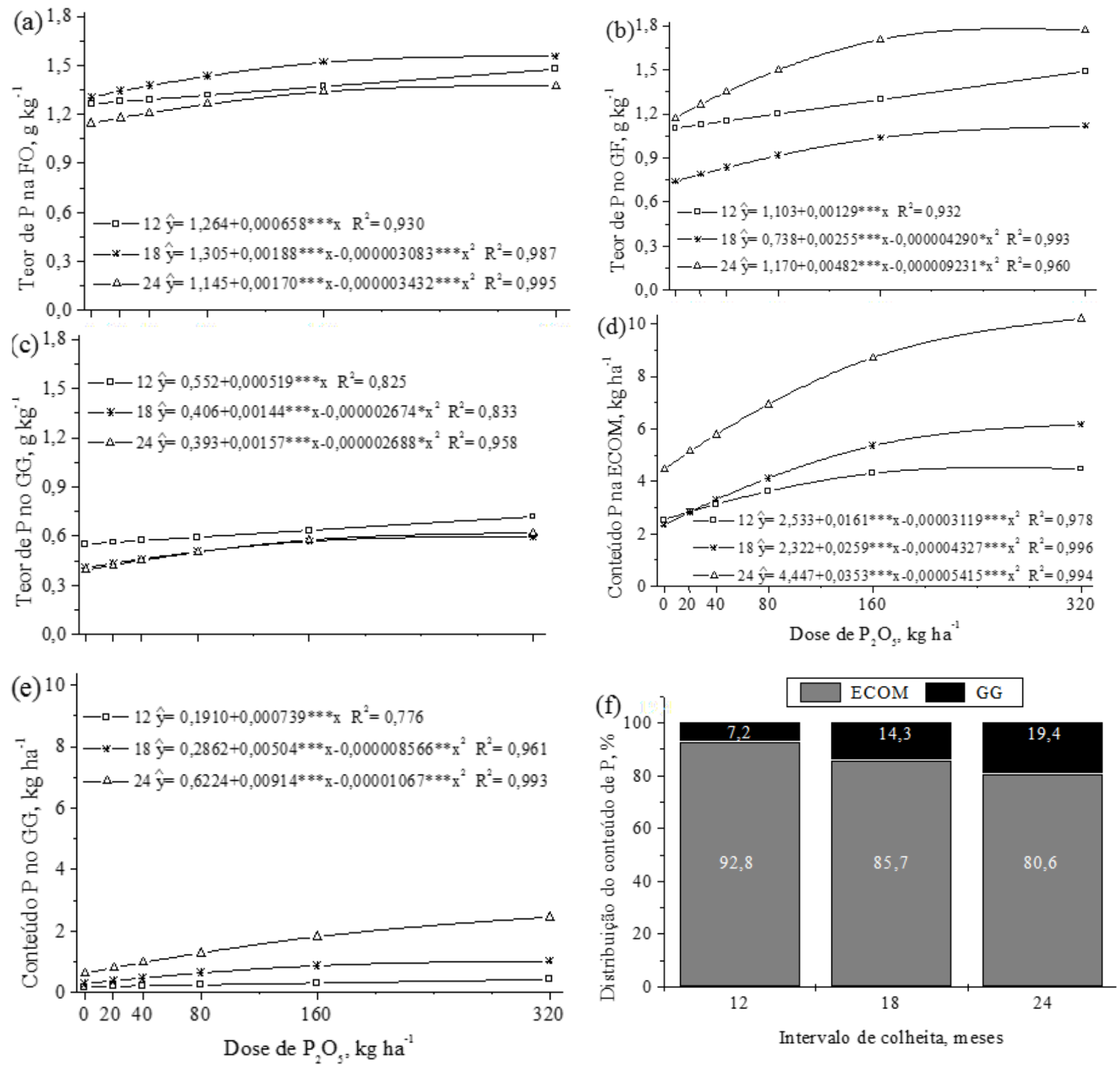

FIGURA 4: Teor de P nas folhas (FO) (a), galhos finos (GF) (b) e galhos grossos (GG) (c); e conteúdo de P na erva-mate comercial (ECOM) (d) e no GG (e); e distribuição do conteúdo de P na ECOM e GG na dose de máxima produtividade de ECOM para cada intervalo de colheita (f) em plantio de erva-mate com intervalos entre colheitas de 12,18 e 24 meses submetidos à adubação fosfatada. *, ** e ***, respectivamente, significativo a $5,1,0,1 \%$ de probabilidade.

FIGURE 4: P content in leaves (FO) (a), thin branches (GF) (b) and thick branches (GG) (c); and P content in commercial mate components (ECOM) (d) and GG (e) and distribution of P content in ECOM and GG on a maximum dose of ECOM productivity for each harvest interval (f) in mate plantation with 12,18 and 24 months intervals between harvests under fertilization. *, $* *$ and $* * *$ respectively, significant at $5,1,0.1 \%$ probability. 
relação ao de ECOM, consequentemente, favorecerão a redução da ECOM/GG.

A adubação fosfatada elevou o teor total de $\mathrm{P}$ no tecido vegetal de todos os componentes em todos os intervalos de colheita (Figuras $4 \mathrm{a}, \mathrm{b}, \mathrm{c}$ ). O conteúdo de P na ECOM e no GG também aumentou com as doses de $\mathrm{P}_{2} \mathrm{O}_{5}$ (Figuras $4 \mathrm{~d}$, e). Contudo, na distribuição do conteúdo de $\mathrm{P}$ dos componentes colhidos, à medida que o intervalo entre colheitas aumentou a participação do GG também foi maior (Figura 4f).

$\mathrm{O}$ teor de $\mathrm{P}$ foliar aumentou linearmente com as doses no intervalo entre colheitas de 12 meses. No intervalo de 18 e 24 meses, o teor máximo, respectivamente, de 1,6 e 1,3 $\mathrm{g} \mathrm{kg}^{-1}$ ocorreu na dose de 305 e $248 \mathrm{~kg} \mathrm{ha}^{-1}$ de $\mathrm{P}_{2} \mathrm{O}_{5}$ (Figura 4a). O teor de $\mathrm{P}$ no galho fino (GF) no intervalo de 12 meses manteve a mesma tendência do teor foliar. No intervalo de 24 meses, com teor máximo de $1,8 \mathrm{~g} \mathrm{~kg}^{-1}$, ele foi superior ao máximo de $1,1 \mathrm{~g} \mathrm{~kg}^{-1}$ ocorrido no intervalo de 18 meses (Figura 4b). Com teor de P menor que os demais componentes, o GG apresentou para o intervalo de 18 meses o teor mínimo de $0,6 \mathrm{~g} \mathrm{~kg}^{-1} \mathrm{e}$, para o intervalo de 12 meses, o maior teor de $0,7 \mathrm{~g} \mathrm{~kg}^{-1}$ (Figura 4c).

A exportação de $\mathrm{P}$ em cada componente, representada pelo conteúdo de $\mathrm{P}$, apresentou na ECOM o máximo de 4,6, 6,2 e 10,2 $\mathrm{kg} \mathrm{ha}^{-1}$, respectivamente, nos intervalos de 12, 18 e 24 meses (Figura 4d). Para o GG, o conteúdo máximo de 0,4, 1,0 e 2,4 $\mathrm{kg} \mathrm{ha}^{-1}$ ocorreu, respectivamente, nos intervalos de 12, 18 e 24 meses (Figura 4e). Em colheitas com intervalo de 12 meses, o conteúdo de P no galho representa uma pequena fração (7,2 \%), comparado ao conteúdo na ECOM. Por outro lado, em colheitas com intervalo de 24 meses a exportação de P pelo GG atinge 19,4 \% do total dos componentes colhidos da copa da planta (Figura 4f).

A resposta da erva-mate à adubação fosfatada sempre foi tida como pouco provável. Em experimento com doses de P, realizados por Pandolfo et al. (2003), com cultivo em fase de produção em solo muito argiloso e disponibilidade inicial de $\mathrm{P}$ de $4,2 \mathrm{mg} \mathrm{L}^{-1}$, não houve resposta positiva e doses anuais em torno de $50 \mathrm{~kg} \mathrm{ha}^{-1}$ seriam suficientes para manter uma boa produtividade. No entanto, os resultados obtidos neste trabalho mostram que em solo com baixa disponibilidade de $\mathrm{P}$, há resposta da erva-mate à adubação fosfatada. Considerando a dose, associada à maior produtividade de ECOM, de 219, 283 e $320 \mathrm{~kg} \mathrm{ha}^{-1}$ (Figura 2d), respectivamente, para colheitas com intervalos de 12, 18 e 24 meses, os respectivos teores de P no solo obtidos na profundidade de $0-10 \mathrm{~cm}$ de $6,9,10,5$ e 10,1 $\mathrm{mg} \mathrm{dm}^{-3}$ são classificados como nível alto (COMISSÃO DE QUÍMICA E FERTILIDADE DO SOLO, 2004). Em levantamento de produtividade de erva-mate realizado por Lourenço (1997) nos Estados do Sul do Brasil, produtividades anuais de 35,7 e 32,7 $\mathrm{t} \mathrm{ha}^{-1}$ com teores de $\mathrm{P}$ no solo, respectivamente de 30,0 e 7,0 $\mathrm{mg} \mathrm{dm}^{-3}$, também indica que altas produtividades de erva-mate dependem de boa disponibilidade de $\mathrm{P}$ no solo. A suposta baixa exigência da erva-mate ao P (REISSMANN et al., 1983; RADOMSKI et al., 1992) se contrapõe ao verificado por Lourenço (1997) e aos resultados aqui apresentados. Aparentemente, em ambiente natural, em solos com baixa disponibilidade de $\mathrm{P}$, a erva-mate absorve $\mathrm{P}$ de formas orgânicas do solo e o cicla de forma eficiente, criando um bom status nutricional das plantas. No entanto, em plantios, produtividades elevadas de ervamate dependem de teores de $\mathrm{P}$ disponíveis no solo em nível alto.

A demanda de $\mathrm{P}$ e a resposta à adubação fosfatada da erva-mate podem variar em função da idade da copa em que é efetuada a colheita. Em termos de resposta à adubação fosfatada, a ECOM.PIC de 6,3, 7,1 e 12,4 $\mathrm{t} \mathrm{ha}^{-1}$, respectivamente, em 12, 18 e 24 meses (Figura 2e), quando comparada a ECOM.PID máxima do efeito dose (Figura 2f), proporcionou aumento respectivo de 61,86 e $87 \%$ da produtividade de ECOM (Figura $2 \mathrm{~d}$ e Tabela 2). A menor resposta à adubação no intervalo de 12 meses é indicativa que neste período de tempo, mesmo bem nutrida em $\mathrm{P}$, a planta não conseguiria recompor a parte aérea e a radicular a tempo para obter boa produtividade na colheita seguinte. Neste caso, a baixa produtividade não estaria relacionada a restrições nutricionais, mas sim, a limitação fotossintética causada pela reduzida área foliar (EPSTEIN; BLOOM, 2004), provocada pelo desequilíbrio entre copa e raízes, requerendo uma reação compensatória da planta (MILANO; DALCIN, 2000), o que só ocorreu nas colheitas com maiores intervalos de tempo. Contudo, em manejos de colheita menos drásticos, ou seja, que permaneça na planta maior quantidade de folhas, possivelmente a resposta à adubação seja maior. Isso merece estudo especial, pois, a proporção de copa removida na colheita pode ser mais um fator que contribua no aumento da produtividade de erva-mate.

A menor EUP e a TR.pl de P no intervalo de 12 meses indicam que colheitas com menor intervalo de tempo são pouco recomendadas para a cultura da erva-mate. Considerando a dose de produtividade máxima de ECOM (Figura 2d), nos intervalos de 12, 18 e 24 meses, a respectiva EUP foi de 781, 921 e $878 \mathrm{~kg} \mathrm{~kg}^{-1}$ 
TABELA 2: Aumento da produtividade de erva-mate comercial (ECOM) e galho grosso (GG) verde. TABLE 2: Productivity increment of commercial mate (ECOM) and green thick branch (GG).

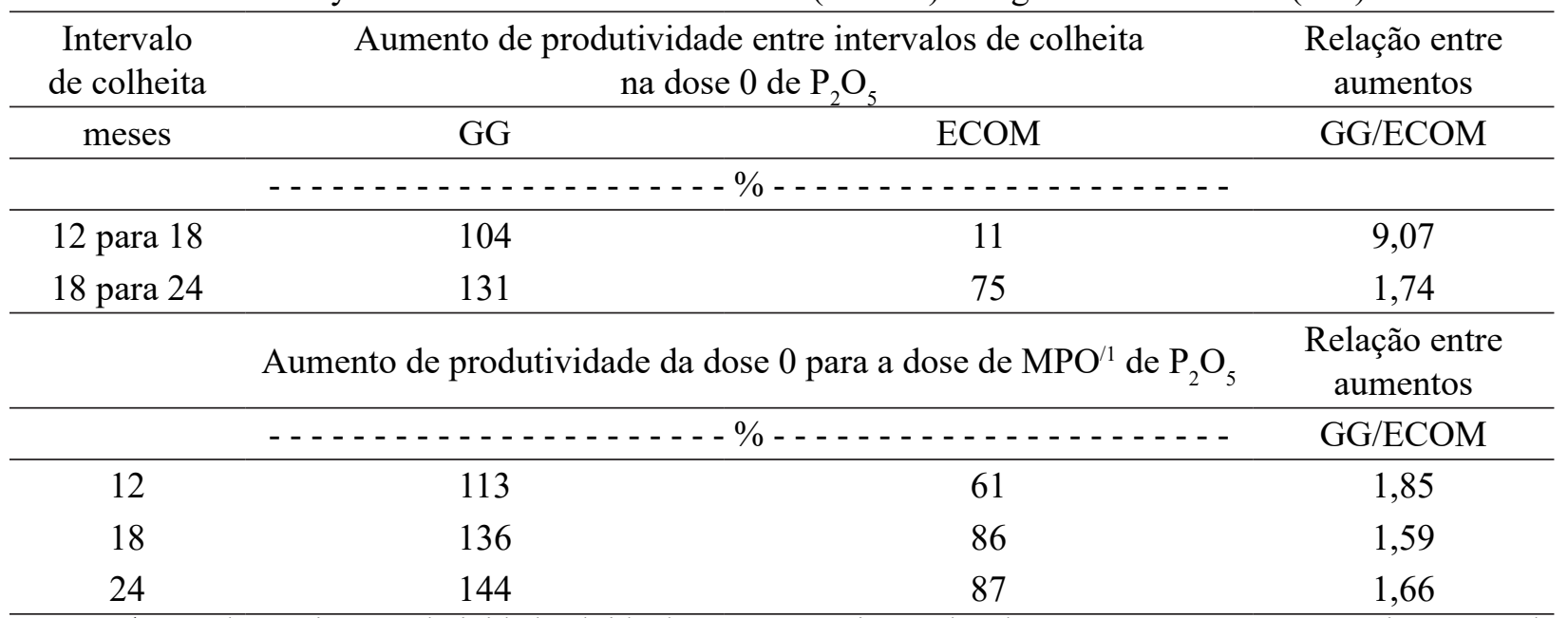

Em que: 'Dose de máxima produtividade obtida de ECOM nos intervalos de 12, 18 e 24 meses, respectivamente, de 219,282 e $320 \mathrm{~kg} \mathrm{ha}^{-1}$ de $\mathrm{P}_{2} \mathrm{O}_{5}$ (Figura 2d).

de P (Figura 3a). Nesta mesma condição (dose de produtividade máxima de ECOM), nos intervalos de 12, 18 e 24 meses, a TR.pl foi de 1,9, 3,2 e 5,6 \% do P aplicado, respectivamente (Figura 3f). A redução da EUP e da TR.pl ocorreu, tanto para menores intervalos de colheita, como maiores doses do fertilizante (Figura 3a). A redução da EUP com aumento da disponibilidade de P é reflexo que, em limitação nutricional, sob pequenas doses de fertilizantes as plantas aumentam a absorção de nutrientes e a produção de forma linear (VAN KEULEN, 1982). Contudo, sob alta disponibilidade de nutrientes as plantas os absorvem além de sua demanda, reduzindo eficiência de seu uso (EPSTEIN; BLOOM, 2004) e também a TR.pl (TEIXEIRA et al., 2002). Plantas em fase adulta, quando comparadas às de fase inicial de crescimento, apresentam maior TR.pl em consequência do sistema radicular já estabelecido (PREZOTTI, 2001; ROSA, 2002), cuja capacidade de exploração do solo é maior. A maior EUP (Figura 3a) e a maior TR.pl (Figura 3f) verificadas nos maiores intervalos de tempo entre colheitas indicam que as plantas de erva-mate colhidas com intervalo de 12 meses teriam sistema radicular menos volumoso, o que restringe a absorção de nutrientes.

A semelhança na relação de MV/MS de FO (Figura 3b) e ECOM (Figura 3c) com maior valor para o intervalo de 18 meses quando não adubado, fato não manifestado nos demais intervalos, possivelmente esteja relacionada à época do ano em que as colheitas foram efetuadas. No intervalo de 18 meses, a colheita foi efetuada em agosto (inverno) e nos demais intervalos em janeiro (verão). Na erva-mate ocorrem duas fases de crescimento no ano, primaveril e outonal, sendo o início de cada fase, respectivamente em setembro e janeiro (RAKOCEVIC; MARTIM, 2011). A colheita do intervalo de 18 meses foi efetuada no inverno, época em que as plantas de erva-mate se encontram em menor atividade fisiológica (REISSMANN et al., 1983; RAKOCEVIC; MARTIM, 2011), condição que se esperava menor MV/MS na colheita efetuada no inverno, que as colhidas no verão (intervalo de 12 e 24 meses).

$\mathrm{O}$ aumento do valor de FO/GF com a idade da copa (Figura 3e) pode estar relacionado a uma maior proporção de folhas maduras. Reissmann et al. (1985), ao avaliarem, após um ano da colheita, o peso de 100 folhas coletadas mensalmente durante 12 meses, constataram aumento de $50 \%$ da massa da folha. Assim, colheitas com intervalos de tempo maiores, tendem a aumentar a massa da folha, repercutindo no aumento da relação $\mathrm{FO} / \mathrm{GF}$ e na composição da ECOM.

Com o aumento do intervalo de tempo entre colheitas, há também aumento da EUP (Figura 3a) e da relação $\mathrm{FO} / \mathrm{GF}$, o que é de interesse do produtor e da indústria. Porém, ocorre, paralelamente, a redução da relação ECOM/GG com o maior intervalo, fato pouco interessante para o produtor. Na dose de máxima produtividade de ECOM, a relação ECOM/GG de 5,3, 3,1 e 2,3, respectivamente, nos intervalos de 12, 18 e 24 meses (Figura 3d), demonstra que à medida que a planta aumenta a massa de folha e galho fino 
(ECOM), maior será o gasto em energia na produção de GG para sustentar os demais componentes da copa. Entretanto, não é raro na cultura da erva-mate, verificarem-se relações de ECOM/GG muito mais estreitas, como valores de 1,0 e 1,2 observados por Santin et al. (2011) em plantios com cinco anos de idade e colheitas realizadas a cada 24 meses. No entanto, parece que o aumento da produtividade de ECOM é sempre dependente de um maior aumento da produtividade de GG (Tabela 2), aumento esse ocasionado, tanto pela adubação como pelo intervalo de colheita. Nota-se que o percentual de aumento do GG entre os intervalos de colheita é muito maior do que o aumento da ECOM. Quando a erva-mate não é adubada com $\mathrm{P}$, o aumento de 1 unidade da ECOM, do intervalo de 12 para 18 meses, ocorreu quando houve mais de 9,0 unidades de aumento do GG, mas no intervalo de 18 para 24 meses, esse aumento foi de 1,7 unidades. Quando esta comparação é feita dentro de cada intervalo de colheita em função da dose de P, os intervalos de 12 e 24 meses proporcionaram maior aumento da produção de GG por aumento de unidade de ECOM.

$\mathrm{O}$ teor de $\mathrm{P}$ foliar, considerando a dose de máxima produtividade de ECOM de cada intervalo de colheita, variou de 1,3 a $1,5 \mathrm{~g} \mathrm{~kg}^{-1}$ (Figura 4a). Os relatos de baixos teores foliares de $\mathrm{P}$ na erva-mate acompanham essa cultura desde os primeiros trabalhos realizados com caracterização nutricional. Teores foliares de $\mathrm{P}$ de 1,1 $\mathrm{g} \mathrm{kg}^{-1}$ (REISSMANN et al., 1983), 1,4 $\mathrm{g} \mathrm{kg}^{-1}$ (REISSMANN et al., 1985), 0,8 $\mathrm{g} \mathrm{kg}^{-1}$ (BRONDANI et al., 2008) e 1,4 $\mathrm{g} \mathrm{kg}^{-1}$ (SANTIN, 2008), considerados baixos por esses autores, talvez sejam adequados levando-se em conta que a espécie naturalmente ocorre em solos muito pobres em $\mathrm{P}$ (CARVALHO, 2003). Levantamentos realizados em diferentes locais, mostraram teores foliares de $\mathrm{P}$ entre 0,5 a 3,2 $\mathrm{g} \mathrm{kg}^{-1}$ em 16 cultivos no estado do Paraná (REISSMANN et al., 1999), e entre 0,8 a 2,4 $\mathrm{g} \mathrm{kg}^{-1}$, em 20 cultivos das principais regiões produtoras do Sul do Brasil (LOURENÇO, 1997). Esses resultados mostram que, na erva-mate, os teores de $\mathrm{P}$ foliar, normalmente ditos baixos, quando se situam entre 1,3 a $1,5 \mathrm{~g} \mathrm{~kg}^{-1}$, podem ser tidos como adequados para a espécie.

O teor máximo de P no GF na dose de máxima produtividade de ECOM, de 1,4, 1,1 e 1,7 $\mathrm{g} \mathrm{kg}^{-1}$, respectivamente, nos intervalos de 12, 18 e 24 meses (Figura 4b), assemelha-se ao da FO. Com 0,8 $\mathrm{g} \mathrm{kg}^{-1}$ Reissmann et al. $(1983 ; 1985)$ também já haviam relatado semelhança dos teores de $\mathrm{P}$ no galho e folha. Nessa condição, em que a erva-mate sempre apresentou baixos teores de P foliar, os GF podem ser uma importante fonte de reserva à planta. A translocação do $\mathrm{P}$ do GF para a FO pode ser importante mecanismo para suprir, em parte, a demanda da planta. Esta hipótese se reforça pela superioridade do teor de $\mathrm{P}$ do GF, quando comparado ao do GG, que não ultrapassou a $0,7 \mathrm{~g} \mathrm{~kg}^{-1}$ (Figura 4c), sendo ambos os componentes oriundos do mesmo órgão da planta.

O conteúdo de P na ECOM, quando comparado ao de outros macronutrientes torna-se quase insignificante em termos quantitativos. Em cultivo com produtividade de 32,6 t ha ${ }^{-1}$ Lourenço (1997) quantificou a exportação pela ECOM de N, P e K em, respectivamente, 168,16 e $140 \mathrm{~kg} \mathrm{ha}^{-1}$. A baixa exportação de $\mathrm{P}$, reflexo dos baixos teores presentes nos componentes que formam a ECOM, não deve ser desprezada no que tange à reposição do nutriente no cultivo. Neste trabalho, mesmo sem incorporar doses de $320 \mathrm{~kg} \mathrm{ha}^{-1}$ de $\mathrm{P}_{2} \mathrm{O}_{5}$, proporcionou-se disponibilidade máxima de $\mathrm{P}$ de $12,6 \mathrm{mg} \mathrm{dm}^{-3}$ na camada superficial de 0-10 cm de solo. Mesmo com a aplicação superficial concentrada na faixa de projeção da copa, provavelmente grande parte do $\mathrm{P}$ aplicado não ficou disponível para a planta. Neste contexto, na recomendação de adubação para a cultura da erva-mate, baseada na reposição do nutriente exportado pela colheita, deve-se considerar a taxa de recuperação do nutriente aplicado via fertilizante. A relação entre a dose de $\mathrm{P}$ adicionada para atingir a máxima produtividade de ECOM e a quantidade exportada do nutriente nesta mesma dose e componente variou de 21:1 para o intervalo de 12 meses e de 14:1 no intervalo de 24 meses. É importante lembrar que neste estudo o solo muito argiloso e com alta acidez apresentava características propensas à adsorção de P (NOVAIS; SMYTH, 1999; SOUZA et al., 2006; NOVAIS; MELLO, 2007; RHEINHEIMER et al., 2008). Portanto, estas relações não devem ser extrapoladas para qualquer solo, pois devem mudar conforme as características do solo e do cultivo.

Em colheitas com intervalos de 12 meses a quantidade de massa produzida de GG é insignificante para justificar sua retirada da área de cultivo. Contudo, com o aumento da produtividade, e consequente maior proporção de GG do que de COM, como acontece em colheitas a partir de intervalos de 18 meses, a retirada de GG requer a reposição do P exportado. A isto deve ser somado o P exportado pela colheita da ECOM, isto é, 14 e $19 \%$, respectivamente para colheitas com 18 e 24 meses. 


\section{CONCLUSÕES}

O aumento da disponibilidade de fósforo decorrente da adubação fosfatada, mesmo com doses de $320 \mathrm{~kg} \mathrm{ha}^{-1} \mathrm{de}_{2} \mathrm{O}_{5}$, se restringe às camadas superficiais do solo.

Alta produtividade de cultivos de erva-mate é dependente de disponibilidade de fósforo em nível alto na camada superficial do solo, independentemente do intervalo de colheita.

Em solos argilosos e com baixa disponibilidade de $\mathrm{P}$, recomendam-se doses menores de $220 \mathrm{~kg} \mathrm{ha}^{-1}$ de $\mathrm{P}_{2} \mathrm{O}_{5}$ para colheitas com intervalo de 12 meses. Nas colheitas, com intervalo de 18 meses, as doses de $\mathrm{P}_{2} \mathrm{O}_{5}$ devem estar abaixo de $290 \mathrm{~kg} \mathrm{ha}^{-1}$ e com intervalos de 24 meses, as doses podem superar $320 \mathrm{~kg} \mathrm{ha}^{-1}$ do nutriente.

O impacto da remoção da copa pela colheita é minimizado pela adubação fosfatada. Intervalo entre colheitas de 12 meses é insuficiente para recomposição da copa e recuperação da planta.

Para colheitas com intervalo de 18 meses, a adubação fosfatada reduz a relação entre massas verde e seca. Cultivos colhidos com intervalos de 12 meses produzem erva-mate comercial com maior proporção de galho fino, comparados aos colhidos a cada 24 meses.

Teor foliar de fósforo entre 1,2 a 1,6 $\mathrm{g} \mathrm{kg}^{-1}$ indica boa condição nutricional das plantas de erva-mate.

\section{AGRADECIMENTOS}

A Agropecuária Vier Ltda. e a Baldo S.A. de São Mateus do Sul - PR, a Embrapa Florestas de Colombo - PR, ao Departamento de Solos da UFV de Viçosa - MG e ao CNPq que possibilitaram a realização do trabalho.

\section{REFERÊNCIAS}

ANDRADE, F. M. Diagnóstico da cadeia produtiva da Ilex paraguariensis St. Hill, erva-mate. São Mateus do Sul: FUNBIO, 1999.

BARROS, N. F. et al. Classificação nutricional de sítios florestais - Descrição de uma metodologia. Revista Árvore, Viçosa, MG, v. 10, n. 2, p. 112-120, 1986.

BRAGA, J. M.; DE FILIPPO, B. V. Determinação espectrofotométrica de fósforo em extratos de solo e plantas. Ceres, Viçosa, MG, v. 21, n. 113, p. 73-85, 1974.

BRONDANI, G. E. et al. Distribuição de NPK em um povoamento de Ilex paraguariensis A. St.-Hil. Floresta, Curitiba, v. 38, n. 2, p. 267-275, 2008.

CARVALHO, P. H. R. Espécies arbóreas brasileiras. Brasília: Embrapa Informação tecnológica; Colombo: Embrapa Florestas, 2003. 1039 p.

CHEPKWONY, C. K. et al. Mineralization of soil organic P induced by drying and rewetting as a source of plant-available P in limed and unlimed samples of an acid soil. Plant and Soil, Dordrecht, v. 234, n. 1, p. 83-90, 2001.

COMISSÃO DE QUÍMICA E FERTILIDADE DO SOLO. Manual de adubação e calagem para os Estados do Rio Grande do Sul e Santa Catarina. 10. ed. Porto Alegre: SBCS/Núcleo Regional Sul, 2004. $400 \mathrm{p}$.

DA CROCE, D. M.; FLOSS, P. A. Cultura da erva-mate no Estado de Santa Catarina. Florianópolis: Epagri, 1999. (Boletim Técnico, 100).

DEITOS, N. J. Considerações históricas da erva-mate no espaço meridional. In: ROCHA JUNIOR, W.; MILOCA, L. M. Sistema agroindustrial ervateiro: perspectivas debates. Cascavel: Coluna do Saber, 2007. p. 13-26.

EPSTEIN, E.; BLOOM, A. J. Nutrição mineral de plantas: princípios e perspectivas. 2. ed. Londrina: Planta, 2004. 403 p.

GAZETA GRUPO DE COMUNICAÇÕES. Anuário Brasileiro da Erva-mate 1999. Santa Cruz do Sul: Pallotti, 1999. 64 p.

GONÇALVES, J. L. M. et al. Cinética de adsorção de fósforo em solos de serrados. Revista Brasileira de Ciência do Solo, Campinas, v. 9, n. 2, p. 107-111, 1985. 
INSTITUTO AGRONÔMICO DO PARANÁ. Cartas climáticas básicas do Estado do Paraná. Londrina. IAPAR, 1994. 49 p.

IBGE. Produção agrícola municipal. [2015]. Disponível em: <http://www.sidra.ibge.gov.br/bda/tabela/ listabl.asp? $\mathrm{c}=106 \& \mathrm{z}=\mathrm{p} \& \mathrm{o}=28>$. Acesso em: 10 abr. 2015.

LOURENÇO, R. S. Adubação da erva-mate. In: CONGRESSO SUL-AMERICANO DA ERVA-MATE, 1.; REUNIÃO TÉCNICA DO CONESUL SOBRE A CULTURA DA ERVA-MATE, 2., 1997, Curitiba. Anais... Curitiba: EMBRAPA; CNPF, 1997. p. 299-315.

MILANO, M.; DALCIN, E. Arborização de vias públicas. Rio de Janeiro: Light, 2000. 206 p.

NOVAIS, R. F.; MELLO, J. W. V. Relação solo-planta. In: NOVAIS, R. F. et al. Fertilidade solo. Viçosa, MG: SBCS, 2007. p. 276-374.

NOVAIS, R. F.; SMYTH, T. J. Fósforo em solos e planta em condições tropicais. Viçosa, MG: UFV, 1999. $399 \mathrm{p}$.

NOVAIS, R. F. et al. Fósforo. In: NOVAIS, R. F. et al. (Eds.). Fertilidade solo. Viçosa, MG: SBCS, 2007. p. 471-550.

PANDOLFO, M. C. et al. Resposta da erva-mate (Ilex paraguariensis St. Hil.) à adubação mineral e orgânica em um Latossolo Vermelho alumino férrico. Ciência Florestal, Santa Maria, v. 13, n. 2, p. 37-45, 2003.

PREZOTTI, L. C. Fertilização do cafeeiro. In: ZAMBOLIM, L. Tecnologias de produção de café com qualidade. Viçosa, MG: UFV, 2001. p. 607-615.

RAKOCEVIC, M.; MARTIM, S. F. Time series in analysis of yerba-mate biennial growth modified by environment. International Journal of Biometeorology, Wisconsin, v. 55, n. 2, p. 161-171, 2011.

RADOMSKI, M. I. et al. Avaliação dos teores de macro e micronutrientes em folhas jovens e velhas de erva-mate nativa. Revista do Instituto Florestal, São Paulo, v. 4, nesp, p. 453-456, 1992.

REISSMANN, C. B. et al. Avaliação da exportação de macronutrientes pela exportação da erva-mate. In: SEMINÁRIO SOBRE ATUALIDADES E PERSPECTIVAS FLORESTAIS, 1985, Curitiba. Anais... Curitiba: EMBRAPA; CNPF, 1985. p. 128-139.

REISSMANN, C. B. et al. Bio-elementos em folhas e hastes de erva-mate (Ilex paraguariensis St. Hil.) sobre Cambissolo na região de Mandirituba - PR. Floresta, Curitiba, v. 14, n. 2, p. 49-54, 1983.

REISSMANN, C. B. et al. Chemical composition of Ilex paraguariensis St. Hil. Under different management conditions in seven localities of Paraná State. Brazilian Archives of Biology and Technology, Curitiba, v. 42, n. 2, p. 187-194, 1999.

RHEINHEIMER, D. S.; ANGHINONI, I. Accumulation of soil organic phosphorus by soil tillage and cropping systems in subtropical soils. Communications in Soil Science and Plant Analysis, Philadelphia, v. 34, n. 15/16, p. 2339-2354, 2003.

RHEINHEIMER, D. S. et al. Depleção do fósforo inorgânico de diferentes frações provocada pela extração sucessiva com resina em diferentes solos e manejos. Revista Brasileira de Ciência do Solo, Viçosa, MG, v. 24, n. 2, p. 345-354, 2000.

RHEINHEIMER, D. S. et al. Fatores que afetam a disponibilidade do fósforo e o manejo da adubação fosfatada em solos sob sistema plantio direto. Ciência Rural, Santa Maria, v. 38, n. 2, p. 576-586, 2008.

ROSA, G. N. G. P. Sistema de recomendação de corretivos e fertilizantes para o cultivo do coqueiro. 2002. 76 f. Dissertação (Mestrado em Solos e Nutrição de Plantas) - Universidade Federal de Viçosa, Viçosa, 2002.

SANTIN, D. et al. Crescimento e nutrição de erva-mate influenciados pela adubação nitrogenada, fosfatada e potássica. Ciência Florestal, Santa Maria, v. 23, n. 2, p. 363-375, 2013.

SANTIN, D. et al. Nitrogênio, fósforo e potássio no crescimento de mudas de erva-mate. Scientia Agraria, Curitiba, v. 9, n. 1, p. 59-66, 2008.

SANTIN, D. Produtividade, teor de minerais, cafeína e teobromina em erva-mate adensada e adubada quimicamente. 2008. 114 f. Dissertação (Mestrado em Ciências do Solo) - Universidade Federal do Paraná, Curitiba, 2008.

SANTIN, D. et al. Produtividade de erva-mate com mudas produzidas por miniestacas juvenis e por sementes. In: CONGRESO SUDAMERICANO DE LA YERBA MATE, 5., 2011, Posadas. Actas... Posadas: INYM; INTA; INaM, 2011. p. 85-90.

SANTOS, J. Z. L. et al. Frações de fósforo em solo adubado com fosfatos em diferentes modos de aplicação 
e cultivado com milho. Revista Brasileira de Ciência do Solo, Viçosa, MG, v. 32, n. 2, p. 705-714, 2008. SATTERTHWAITE, F. E. An approximate distribution of estimates of variance components. Biometrics Bulletin, London, v. 2, p. 110-114, 1946.

SCWERTMANN, U.; TAYLOR, R. M. Iron oxides. In: BIGHAM, J. M. et al. (Eds.). Minerals in soil environmental. Madison: SSSA, 1989. p. 379-478.

SOUZA, R. F. et al. Calagem e adubação orgânica: influência na adsorção de fósforo em solos. Revista Brasileira de Ciências do Solo, Viçosa, MG, v. 30, n. 6, p. 975-983, 2006.

TEIXEIRA, L. A. J. et al. Parcelamento da adubação NPK em abacaxizeiro. Revista Brasileira Fruticultura, Jaboticabal, v. 24, n. 1, p. 219-224, 2002.

TIECHER, T. et al. Forms of inorganic phosphorus in soil under different long term soil tillage systems and winter crops. Revista Brasileira de Ciência do Solo, Viçosa, MG, v. 36, n. 1, p. 271-281, 2012.

VAN KEULEN, H. Graphical analysis of annual crop response to fertilizer application. Agricultural Systems, Essex, v. 9, n. 2, p. 113-126, 1982.

VILAR, C. C. et al. Capacidade máxima de adsorção de fósforo relacionada a formas de ferro e alumínio em solos subtropicais. Revista Brasileira de Ciência do Solo, Viçosa, MG, v. 34, n. 4, p. 1059-1068, 2010. 